\title{
Modelling runoff at the plot scale taking into account rainfall partitioning by vegetation: application to stemflow of banana (Musa spp.) plant
}

\author{
J.-B. Charlier ${ }^{1, *}$, R. Moussa ${ }^{2}$, P. Cattan ${ }^{1}$, Y.-M. Cabidoche ${ }^{3}$, and M. Voltz ${ }^{2}$ \\ ${ }^{1}$ CIRAD, UPR Systèmes bananes et ananas, Capesterre-Belle-Eau, Guadeloupe, 97130, France \\ ${ }^{2}$ INRA, Laboratoire d'étude des Interactions Sol-Agrosystème-Hydrosystème (LISAH), UMR SupAgro-INRA-IRD, Bât. 24, \\ 2 place Viala, 34060 Montpellier cedex 1, France \\ ${ }^{3}$ INRA, UR 135 Agropédoclimatique de la Zone Caraïbes, Domaine Duclos, 97170 Petit-Bourg, Guadeloupe (FWI) \\ *now at: Université de Franche-Comté-CNRS/UMR 6249 Chrono-environnement, UFR des Sciences et Techniques, \\ 16 route de Gray, 25030 Besançon cedex, France
}

Received: 26 May 2009 - Published in Hydrol. Earth Syst. Sci. Discuss.: 16 June 2009

Revised: 6 October 2009 - Accepted: 23 October 2009 - Published: 12 November 2009

\begin{abstract}
Rainfall partitioning by vegetation modifies the intensity of rainwater reaching the ground, which affects runoff generation. Incident rainfall is intercepted by the plant canopy and then redistributed into throughfall and stemflow. Rainfall intensities at the soil surface are therefore not spatially uniform, generating local variations of runoff production that are disregarded in runoff models. The aim of this paper was to model runoff at the plot scale, accounting for rainfall partitioning by vegetation in the case of plants concentrating rainwater at the plant foot and promoting stemflow. We developed a lumped modelling approach, including a stemflow function that divided the plot into two compartments: one compartment including stemflow and the related water pathways and one compartment for the rest of the plot. This stemflow function was coupled with a production function and a transfer function to simulate a flood hydrograph using the MHYDAS model. Calibrated parameters were a "stemflow coefficient", which compartmented the plot; the saturated hydraulic conductivity $(K s)$, which controls infiltration and runoff; and the two parameters of the diffusive wave equation. We tested our model on a banana plot of $3000 \mathrm{~m}^{2}$ on permeable Andosol (mean $K s=75 \mathrm{~mm} \mathrm{~h}^{-1}$ ) under tropical rainfalls, in Guadeloupe (FWI). Runoff simulations without and with the stemflow function were performed and compared to 18 flood events from 10 to 140 rainfall $\mathrm{mm}$ depth. Modelling results showed that the stemflow function improved the calibration of hydrographs according to the er-
\end{abstract}

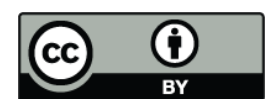

Correspondence to: J.-B. Charlier (jb.charlier@gmail.com) ror criteria on volume and on peakflow, to the Nash and Sutcliffe coefficient, and to the root mean square error. This was particularly the case for low flows observed during residual rainfall, for which the stemflow function allowed runoff to be simulated for rainfall intensities lower than the $K s$ measured at the soil surface. This approach also allowed us to take into account the experimental data, without needing to calibrate the runoff volume on $K s$ parameter. Finally, the results suggest a rainwater redistribution module should be included in distributed runoff models at a larger scale of the catchment.

\section{Introduction}

Many studies have shown the impact of vegetation structure on rainfall partitioning and redistribution at the soil surface (see reviews of Crockford and Richardson, 2000; Levia and Frost, 2003; Llorens and Domingo, 2007). Rainfall intensities at the soil surface are not spatially uniform under vegetation cover, influencing runoff production locally. In this setting, we hypothesized that the concentration of the incident rainfall at the plant foot by stemflow could locally favour runoff. One consequence is that runoff would occur for a lower incident rainfall rate than the infiltration rate of the soil. In this paper we tested hypothesis by modelling at the scale of banana fields, which exhibit large stemflows (Harris, 1997; Cattan et al., 2007a, 2009).

Most runoff simulation models at the plot scale separate incident rainfall $P$ into rainfall excess or surface runoff $S$ and infiltration $I$ (Fig. 1a). For simulation models of Hortonian overland flow - without groundwater contribution -

Published by Copernicus Publications on behalf of the European Geosciences Union. 
this rainfall partitioning at the soil surface depends on the rainfall intensity, the hydrodynamic soil properties, and the initial soil water content. When the soil is close to saturation, $P$ can be separated into $S$ and $I$ with a threshold corresponding to the saturated hydraulic conductivity $K s$. Under vegetation cover, $P$ can be divided into three components (Fig. 1b) before reaching the ground: interception $E_{i}$, which is the water stored in the canopy and completely evaporated before it reaches the soil; stemflow $P_{S f}$, which is the water reaching the ground by running down the stem of trees; and throughfall $P_{T f}$, which is a combination of water reaching the ground directly through gaps (direct precipitation) and of water dripping from leaves and branches. This redistribution of rainfall intensities can generate two opposite effects: on the one hand, a buffering effect of incident rainfall intensities under dense vegetation covers (Keim and Skaugset, 2004) such as in forested contexts with a high interception component; on the other hand, a concentration effect on incident rainfall at the base of the plant (Herwitz, 1986; Cattan et al., 2007a), such as for vegetation covers with a funnelling structure promoting stemflow. Because vegetation redistributes the spatially uniform incident rainfall into non-uniform rainfall at the soil surface, modifying locally the surface water fluxes, it should be accounted for in studies of hydrological processes and models of runoff at the plot scale.

Although runoff models have been developed mainly at the catchment scale, many modelling approaches exist at the plot scale. These modelling approaches are based on two functions. First, a production function simulating the runoffinfiltration partitioning on the basis of various infiltration models (Green and Ampt, 1911; Richards, 1931; Horton, 1933; Philip, 1957; Morel-Seytoux, 1978). The main parameters to simulate runoff are the soil hydrodynamic properties, initial soil moisture conditions, and rainfall intensity. Second, a transfer function routing the generated runoff volume at the outlet of the plot on the basis of the diffuse wave model (Moussa and Bocquillon, 1996) or the kinematic wave model (Singh, 1994). The main parameters to model a hydrograph relate to surface geometry (slope, roughness), leading to flow velocity and diffusivity parameters. Regarding rainfall partitioning, although many infiltration models account for this process in simulations of soil water dynamics (e.g. Bouten et al., 1992; Belk et al., 2007; Sansoulet et al., 2008; Liang et al., 2009), interception and stemflow processes are rarely represented in runoff models. The interception is often modelled using complex approaches, as for example the Rutter model (Rutter et al., 1971) used to simulate rainfall interception in the physically-based distributed SHE model (Abbott et al., 1986) or the Gash model (Gash et al., 1995) used for example at the plot scale by Van Dijk and Bruijnzeel (2001) and Ajayi et al. (2008). These rainfall interception models need meteorological data and structural parameters often unavailable due to the complexity of the conceptual scheme.

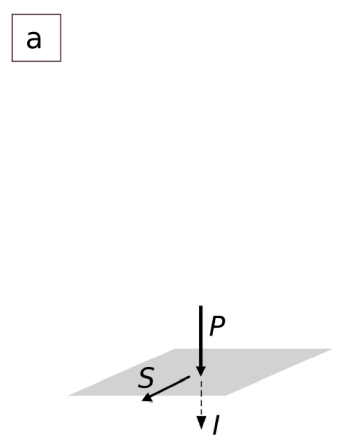

Rainfall partitioning at the soil surface $P=S+1$

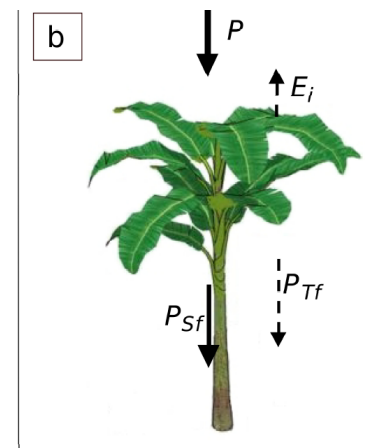

Rainfall partitioning by vegetation $P=P_{S f}+P_{T f}+E_{i}$

Fig. 1. Rainfall partitioning at the soil surface without vegetation (a) and rainfall partitioning under vegetation (b); with rainfall $P$, runoff $S$, infiltration $I$, interception and evaporation $E_{i}$, stemflow $P_{S f}$, and throughfall $P_{T f}$.

In this setting, our aim was to develop a simple hydrological interception/stemflow model, especially adapted for plant promoting stemflow and concentrating rainfall at the plant foot, as banana plant. This model was based on physical and geometrical concepts (accounting for the structure and properties of the plant) rather than on empirical concepts (i.e. Rutter (1971) or Gash (1995) models), and having few parameters. For that, we have developed a stemflow function in the hydrological MHYDAS model (Moussa et al., 2002; Charlier, 2007). This stemflow function redistributes incident rainfall at the soil surface into two compartments: one compartment including stemflow and the related water pathways and one compartment for the rest of the plot. At the plot scale, the model was lumped, considering the plot area as a single entity. The stemflow function was coupled with a production function and a transfer function to simulate discharge at the outlet of the plot. The four main calibrated parameters are the stemflow coefficient, which separates the plot into two compartments with contrasted rainfall fluxes; the saturation hydraulic conductivity at the soil surface; and the two parameters of the diffuse wave equation. We have tested our modelling approach on a banana plot of $3000 \mathrm{~m}^{2}$ located on Andosol in Guadeloupe (FWI, in lesser Antilles), and monitored for rainfall and runoff measurements by Cattan et al. (2006). Banana is a highly redistributive plant with a large stemflow component, increasing rainfall intensities from 18- to 28-fold at the banana foot (Cattan et al., 2007a). Consequently, at the plant scale, stemflow feeds surface water pathways on permeable soils (Cattan et al., 2009) and enhances percolation fluxes at the base of the plant (Cattan et al., 2007b). Calibration and validation of the MHYDAS model were carried out on a set of 18 flood events. The usefulness of the stemflow function was tested by comparing situations without and with stemflow. The paper is organised in four sections: (i) presentation of the model structure, 
(ii) description of the study site, (iii) characterisation of the model behaviour and of the parameter variability, and (iv) comparison of modelling approaches "without" and "with" stemflow.

\section{Model structure}

The modelling approach was based on the MHYDAS model, which is lumped at the plot scale. The model was built on three functions presented in Fig. 2. The first one is the stemflow function, which partitioned incident rainfall into stemflow and throughfall and redistributed these fluxes into two soil compartments. The second one is the production function used to simulate Hortonian runoff at the soil surface without groundwater reaching it - this function was applied separately to each of the two compartments. The third one is the transfer function, which routes the total runoff volume at the outlet of the plot by the diffuse wave equation. The model input is the incident rainfall and the output is a simulated hydrograph, which was compared to the measured hydrograph to test model performances. We present first the stemflow, production, and transfer functions, then a theoretical analysis of the influence of the stemflow function on runoff, and lastly the model properties and calibration procedure.

\subsection{The stemflow function}

\subsubsection{Rainfall partitioning into two compartments}

First, as shown in Fig. 3, rainfall partitioning generates two fluxes at the soil surface: stemflow $P_{S f}$, the flow of water down the stem of a plant, and throughfall $P_{T f}$, which includes leaf drip plus direct precipitation:

$P_{S f}+P_{T f}=P-E_{i}$

$$
\text { in }\left[\mathrm{LT}^{-1}\right]
$$

where the amount $P$ is the incident rainfall and $E_{i}$ is the interception of rainfall that never reaches the soil surface. According to Cattan et al. (2007a), studying the case of banana plant under abundant rainfalls, $E_{i}$ can be neglected at the event time scale, with reference to tropical rainfall volumes; the case study of this paper respects these conditions.

Second, as proposed by Cattan et al. (2009), a twocompartment scheme was considered for modelling runoff (Fig. 3): (i) one compartment of the runoff water pathway fed by stemflow called " $R$ " (like Runoff fed by stemflow) of area $A_{R}$ collecting the rainfall fluxes $P_{R}$ containing the whole stemflow fluxes $P_{S f}$ and the part of throughfall $P_{T f}$ falling on this area, and (ii) one compartment for the rest of the plot called " $N R$ " (like No Runoff fed by stemflow) of area $A_{N R}$ for the rest of the plot collecting the rainfall fluxes $P_{N R}$ containing the other part of throughfall. Let $P_{R}$ and $P_{N R}$ be the two rainfall fluxes reaching areas $A_{R}$ and $A_{N R}$, respectively to be linked to stemflow and throughfall on the plot according to Eq. (2):

$$
P_{R}+P_{N R}=P_{S f}+P_{T f} \quad \text { in }\left[\mathrm{LT}^{-1}\right]
$$

\subsubsection{Calculation of redistributed rainfall intensities on each compartment}

\subsubsection{Hypothesis about the rainfall redistribution at the plot scale}

We hypothesised that stemflow fluxes resulted in a feeding of a surface $A_{R}$ smaller than the whole plot area $A$ with an intensity higher than that of the incident rainfall. The stemflow function partitioned a uniform rainfall intensity $P$ into two fluxes $P_{R}$ and $P_{N R}$ on the areas $A_{R}$ and $A_{N R}$, respectively, with $P_{R}>P_{N R}$. For that, we define $\alpha$ and $\beta$ parameters according to Eqs. (3) and (4):

$P_{R}=\alpha P \quad$ with $\alpha \geq 1 \quad$ in $\left[\mathrm{LT}^{-1}\right]$

$A_{R}=\beta A \quad$ and $\quad A_{N R}=(1-\beta) A \quad$ with $0 \leq \beta \leq 1 \quad$ in $\left[L^{2}\right]$

Parameter $\alpha$ represents the ratio between incident rainfall and effective rainfall on the surface of the runoff pathway fed by stemflow whereas $\beta$ is the proportion of the plot area that is submitted to the influence of stemflow. Equation (3) means that the higher the $\alpha$, the higher the rainfall intensity in $A_{R}$. According to Eq. (4), $\beta$ ranges between 0 and 1, knowing that a value close to 1 corresponds to a model without soil compartmentation (i.e. $A_{R} \approx A$ ) and thus without rainfall redistribution.

In parallel, $P_{N R}$, can be expressed as a function of $P_{R}, A_{R}$ and $A_{N R}$ :

$P_{N R}=\frac{\left(P A-P_{R} A_{R}\right)}{A_{N R}} \quad$ in $\left[\mathrm{LT}^{-1}\right]$

Then, $P_{N R}$ can be expressed as a function of $\alpha$ and $\beta$ substituting $P_{R}$ and $A_{R}$ using Eqs. (3) and (4), respectively:

$$
\begin{aligned}
& P_{N R}=\frac{(P A-\alpha P \beta A)}{(1-\beta) A} \quad \text { in }\left[\mathrm{LT}^{-1}\right] \\
& P_{N R}=\frac{(1-\alpha \beta)}{(1-\beta)} P \quad \text { with } \alpha \geq 1 \quad \text { and } \quad 0<\beta \leq 1 \quad \text { in }\left[\mathrm{LT}^{-1}\right]
\end{aligned}
$$

For $P_{N R}>0$, we set the following condition: $\alpha \beta \leq 1$.

Incident rainfall $P$ is the input variable of the stemflow function and $P_{R}$ and $P_{N R}$ are the two output variables. Parameters $\alpha$ and $\beta$ are the two stemflow function parameters.

\subsubsection{Calculation of the parameters of the stemflow function}

On a plot area A, rainfall partitioning generates two fluxes: stemflow $P_{S f}$ and throughfall $P_{T f}$. We can express $P_{T f}$ as a function of $P_{S f}$ and $P$ :

$$
P_{T f}=\frac{P A-P_{S f} A_{S f}}{A_{T f}}=P\left(\frac{A-\frac{P_{S f}}{P} A_{S f}}{A-A_{S f}}\right) \quad \text { in }\left[\mathrm{LT}^{-1}\right]
$$



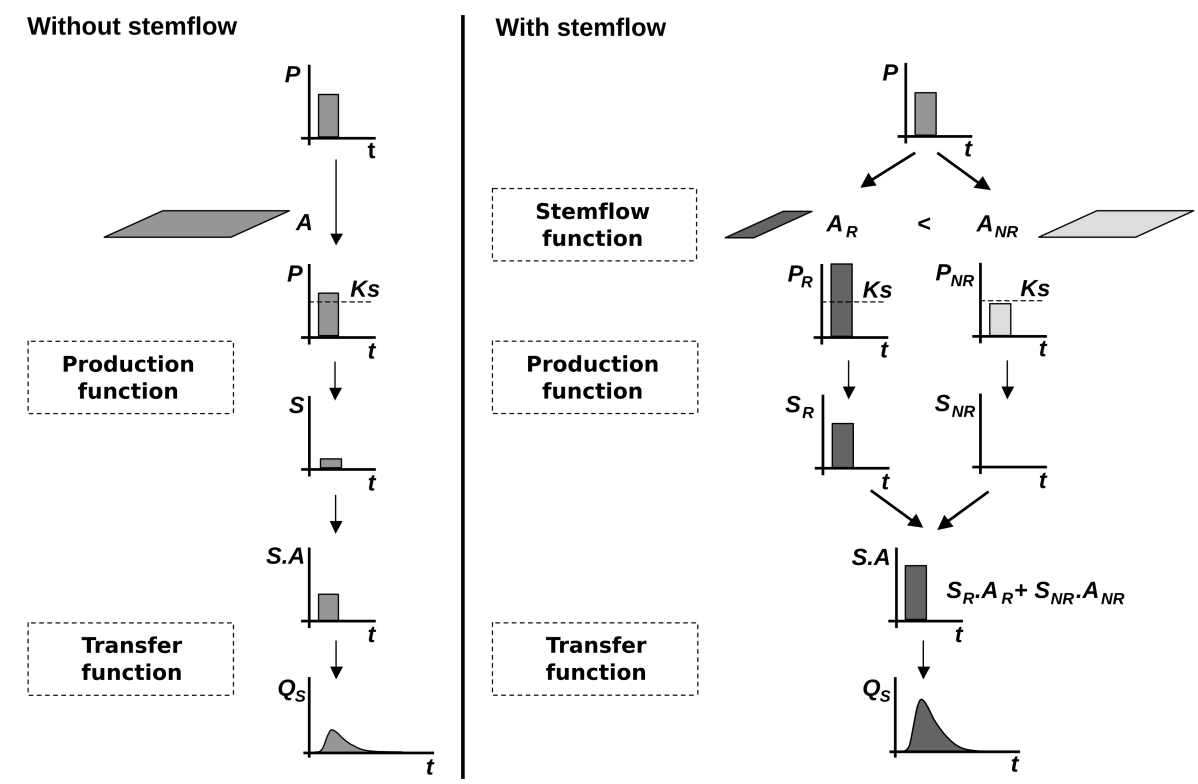

Fig. 2. Model structure without and with a stemflow function, coupled with a production function and a transfer function; with $t$ the time, incident rainfall $P$ reaching the plot of surface area $A$, the saturated hydraulic conductivity $K s$, total runoff $S$ and total infiltration $I$ on the whole plot $A$, the simulated discharge $Q_{S}$ at the outlet of the plot $A$, rainfall intensity $P_{R}$ and $P_{N R}$, runoff $S_{R}$ and $S_{N R}$ on the area $A_{R}$ and $A_{N R} ; A_{R}$ and $A_{N R}$ correspond to the runoff water pathway fed by stemflow (in dark grey color) and the rest of the plot (in light grey color), respectively.

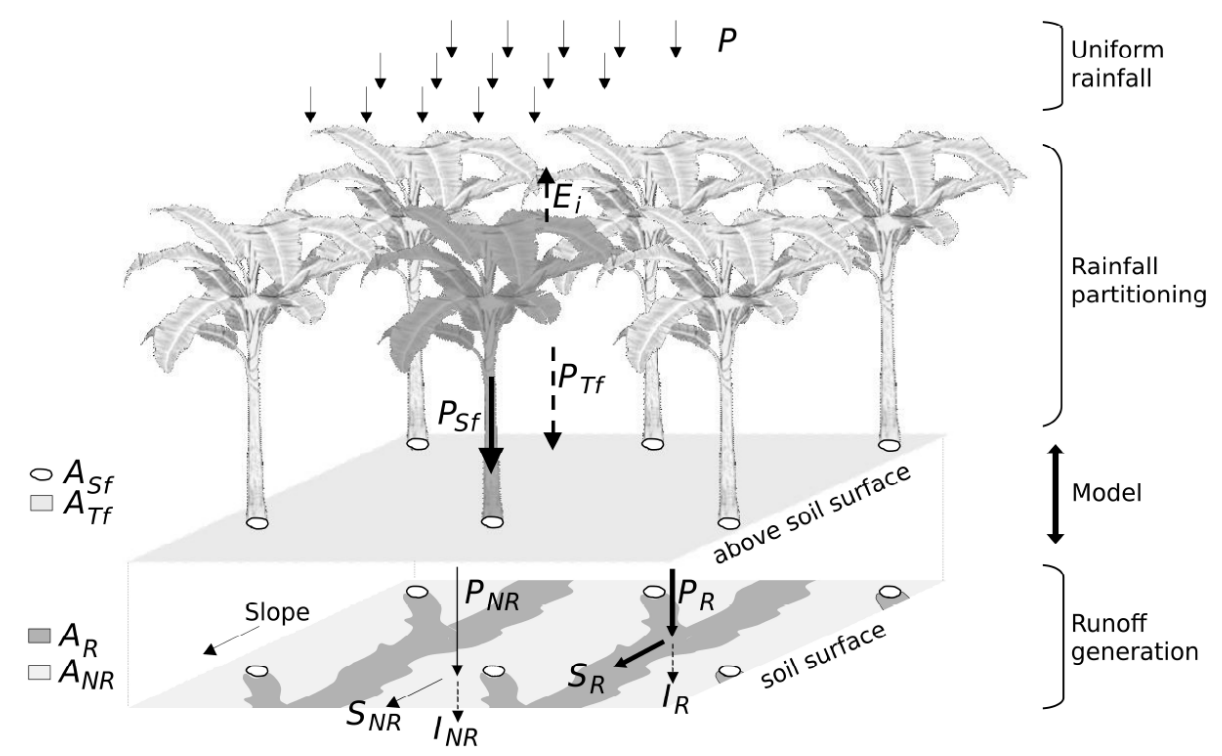

Fig. 3. Water balance at the plot scale; with incident rainfall $P$, interception and evaporation $E_{i}$, stemflow $P_{S f}$, throughfall $P_{T f}$, rainfall intensity $P_{R}$ reaching the area $A_{R}$ corresponding to the runoff water pathway fed by stemflow (in dark grey color), rainfall intensity $P_{I R}$ reaching the area $A_{N R}$ corresponding to the rest of the plot (in light grey color), $S_{R}, I_{R}$, and $S_{I R}$, and $I_{I R}$ the runoff and infiltration on compartments $A_{R}$ and $A_{N R}$, respectively. 
where $A_{S f}$ and $A_{T f}$ are areas where stemflow and throughfall occur, i.e. at the base of the plant, and in the rest of the plot, respectively (see Fig. 3). The rainfall $P_{R}$ reaching $A_{R}$ is expressed according to Eq. (9):

$P_{R}=\frac{P_{S f} A_{S f}+P_{T f}\left(A_{R}-A_{S f}\right)}{A_{R}} \quad$ in $\left[\mathrm{LT}^{-1}\right]$

According to Eqs. (3) and (4), we can express $\alpha$ as a function of $\beta$ by substituting Eqs. (3) and (4) into Eq. (9):

$$
\begin{aligned}
\alpha & =\frac{P_{R}}{P}=\frac{\frac{P_{S f}}{P} A_{S f}+\frac{P_{T f}}{P}\left(A_{R}-A_{S f}\right)}{A_{R}} \\
& =\frac{\frac{P_{S f}}{P} A_{S f}+\frac{P_{T f}}{P}\left(\beta A-A_{S f}\right)}{\beta A}
\end{aligned}
$$

Substituting Eq. (8) into Eq. (10), we have

$$
\alpha=-\frac{1}{\beta}\left[\frac{A_{S f}-\frac{P_{S f}}{P} A_{S f}}{A-A_{S f}}\right]+\left[\frac{A-\frac{P_{S f}}{P} A_{S f}}{A-A_{S f}}\right]
$$

In a general case, the $\alpha$ parameter is expressed as a function of $A, P, P_{S f}$, and $A_{S f}$, which are input parameters, and of $\beta$, which is a calibration parameter. The calibration parameter of the stemflow function $\beta$ is called "stemflow coefficient". The input parameters are characteristic of each cropping plant system, and we detail hereafter the case of a banana plot.

\subsubsection{Parameters of the stemflow function for a banana plot}

According to Eq. (11), input parameters of the stemflow function are detailed for a banana plot. At the banana plant scale, Cattan et al. (2007a) have established an experimental relationship between $P_{S f} / P$ and leaf area index LAI (dimensionless):

$$
\frac{P_{S f}}{P}=11.2 \mathrm{LAI}
$$

On a banana plot planted in a square design $(2.35 \mathrm{~m} \times 2.35 \mathrm{~m})$, the measured values of $A$, LAI, and $A_{S f}$ given by these authors for a banana plant were: $A=2.35 \times 2.35 \mathrm{~m}^{2}$, which represents the elementary area for one banana plant; LAI=3.2 for a full-grown banana plant; $A_{S f}=0.047 \mathrm{~m}^{2}$. For a banana plot, $\alpha$ was thus calculated according to Eqs. (11) and (12), which yields:

$\alpha=\frac{1}{\beta} 0.299+0.701$

\subsubsection{Inputs, parameters, and outputs of the stemflow function}

The inputs of the stemflow function are the incident rainfall $P$, the plot area $A$, the cross-sectional area of the pseudostem at its base $A_{S f}$, and the relationship between $P_{S f} / P$ and LAI
(Eq. 12), which is specific to each plant. The calculated parameter of the stemflow function is $\alpha$, and the calibration parameter is the stemflow coefficient $\beta$. Outputs of the function are the redistributed rainfall intensities $P_{R}$ and $P_{N R}$ in the two soil compartments of $A_{R}$ and $A_{N R}$ areas.

\subsection{The production function}

\subsubsection{Calculation of runoff and infiltration}

Runoff was calculated using the production function on compartments $A_{R}$ and $A_{N R}$ separately. The calculation procedure is detailed for $A_{R}$ only, but it is identical for $A_{N R}$. Hortonian runoff is generated by a rainfall intensity exceeding the saturated hydraulic conductivity $K s$ of the soil surface. Herein, we assume that the soil is close to saturation at the soil surface as often observed under wet climate or in wetland areas. In fact, in a permanent humid context, the initial soil moisture is always close to saturation. Therefore, we considered a constant infiltration capacity at the soil surface equal to $K s$. In this model, the simple production function separates rainfall $P_{R}$ into surface runoff (or stormflow) $S_{R}$ and infiltration $I_{R}$ using the $K s$ threshold. Consequently, the production function is valid only for soils always close to the saturation state and without any influence of the rise of the water table; the following case study located under humid tropical climate respects these conditions.

The variation of $S_{R} / P_{R}$ with time directly depends on the variation of rainfall intensity; $I_{R}$ and $S_{R}$ were determined at each time step according to the following equations:

$$
\begin{array}{ll}
\text { If } P_{R} \leq K s=>P_{R} / K s \leq 1 & \text { then } \quad I_{R}=P_{R} \text { and } \\
S_{R}=0 & \text { in }\left[\mathrm{LT}^{-1}\right]
\end{array}
$$

$$
\begin{aligned}
& \text { If } P_{R}>K s=>P_{R} / K s>1 \quad \text { then } \quad I_{R}=K s \text { and } \\
& S_{R}=P_{R}-K s \quad \text { in }\left[\mathrm{LT}^{-1}\right]
\end{aligned}
$$

On the whole $A$ plot, total runoff $S$ and total infiltration $I$ are given according to Eq. (16):

$$
S=S_{R+} S_{N R} \quad \text { and } \quad I=I_{R}+I_{N R} \quad \text { in }\left[\mathrm{LT}^{-1}\right]
$$

\subsubsection{Inputs, parameters, and outputs of the production function}

As explained in Fig. 2, for areas $A_{R}$ and $A_{N R}$, the inputs of the production function are the redistributed rainfall $P_{R}$ and $P_{N R}$, respectively. $K s$ is the calibration parameter. Runoff depth $S_{R}$ and $S_{N R}$, and infiltration depth $I_{R}$ and $I_{N R}$ are calculated for areas $A_{R}$ and $A_{N R}$, respectively. The output of the function is the total runoff depth $S$. 


\subsection{The transfer function}

\subsubsection{Calculation of the discharge}

A transfer function was used to route the total runoff depth $S$ at the outlet of the plot and to simulate discharge $Q_{S}$. Generally, the full non linear equations of Saint-Venant are used to model flood routing. The choice of a simplification of SaintVenant equation (kinematic or diffusive wave) is often made on pragmatic grounds in that a full Saint-Venant equation needs complex numerical approaches for the resolution of the differential equations, and would be too computationally intensive. The modeller encounters the questions of construction of finite-difference or finite-element systems (Marks and Bates, 2000) and methods for solving them (Cunge et al., 1980). In order to avoid numerical instabilities, the best compromise between the complexity of non-linear model and the simplicity of empirical ones, was a linear diffusive wave as a simplification of the full Saint-Venant equation. Generally, the diffusive wave model has been largely used for flood routing (see Moussa and Bocquillon (2009) for a review). This function is a linear model, based on a Hayami (1951) kernel function, which is a resolution of the diffusive wave equation (Moussa and Bocquillon, 1996). Let $A . S(t)\left[\mathrm{L}^{3} T^{-1}\right]$ be the input hydrograph and $Q_{S}(t)$ the routed hydrograph at the outlet.

$$
\begin{aligned}
& Q_{S}(t)=\int_{0}^{t} A \cdot S(\tau) \cdot H(t-\tau) \cdot d \tau \\
& \text { with } \quad H(t)=\left(\frac{\omega \cdot z}{\pi}\right)^{\frac{1}{2}} \cdot \frac{\exp ^{z\left(2-\frac{t}{\omega}-\frac{\omega}{t}\right)}}{(t)^{3 / 2}}
\end{aligned}
$$

where $H(t)$ is the Hayami kernel function, $\omega[T]$ is a time parameter that represents the centre of gravity of the unit hydrograph called lag time, $z$ [dimensionless] is a form parameter, $\pi=3.1416$, and $t[T]$ is the time. The two parameters of the transfer function are $\omega$ and $z$.

\subsubsection{Inputs, parameters, and output of the transfer function}

The inputs of the transfer function are the simulated runoff depth $S$ and the plot area $A$. The two parameters $\omega$ and $z$ are the calibration parameters of the function. As shown in Fig. 2, the output is the simulated discharge $Q_{S}$.

\subsection{Theoretical analysis of the influence of the stemflow function on runoff}

Herein we discuss the parameters that relate to runoff production in the modelling approach. These parameters are those of the stemflow and the production functions.

If the model does not include a stemflow function, the runoff production is controlled only by the production func- tion. Based on Eqs. (14) and (15), runoff volume $V_{S}$ is produced if $P$ is higher than $K s$ according to following equations:

$\begin{array}{llll}\text { if } P / K s>1 & \text { then } & V_{S}=(P-K s) A & \text { in }\left[L^{3}\right] \\ \text { if } P / K s \leq 1 & \text { then } & V_{S}=0 \quad \text { in }\left[L^{3}\right]\end{array}$

If the model includes a stemflow function, and thus a twocompartment scheme, three cases can be distinguished for runoff production:

(i) First case: if $P_{R} / K s>1$ and $P_{N R} / K s>1, V_{S}$ is expressed as the sum of runoff in areas $A_{R}$ and $A_{N R}$, that is, according to previous Eqs. (3), (4), and (7):

$V_{S}=(\alpha P-K s) \beta A+\left(\left(\frac{1-\alpha \beta}{1-\beta}\right) P-K s\right)(1-\beta) A \quad$ in $\left[L^{3}\right]$

Then we have

$$
V_{S}=\alpha \beta A P+\left(\frac{1-\alpha \beta}{1-\beta}\right)(1-\beta) A P-K s
$$$$
\beta A-K s(1-\beta) A \quad \text { in }\left[L^{3}\right]
$$

and we obtain

$$
V_{S}=(P-K s) A \quad \text { in }\left[L^{3}\right]
$$

This first case corresponds to runoff occurring in $A_{R}$ and in $A_{N R}$. In this case, the model with stemflow including a production function applied on each compartment is thus equivalent to the model without stemflow ( $\beta$ close to 1$)$ including a production function applied on the whole plot. The infiltration rate is thus equal to $K s$. In this case, the model calibration can be performed only by optimising $K s$.

(ii) Second case: if $P_{R} / K s>1$ and $P_{N R} / K s<1$, we have, according to Eqs. (3) and (7)

$\frac{1}{\alpha}<\frac{P}{K s}<\frac{1-\beta}{1-\alpha \beta}$

and in this case $V_{S}$ is expressed as follows:

$V_{S}=(\alpha P-K s) \beta A=\alpha \beta P A-\beta K s A \quad$ in $\left[L^{3}\right]$

In the specific case of a banana plot, substituting

Eq. (13) into Eq. (23) leads to

$\frac{\beta}{0.299+0.701 \beta}<\frac{P}{K s}<\frac{1-\beta}{0.701-0.701 \beta}=\frac{1}{0.701}$

Then, according to Eqs. (13) and (24), we have

$V_{S}=\left(0.701+\frac{0.299}{\beta}\right) \beta P A-\beta K s A \quad$ in $\left[L^{3}\right]$

which simplifies to

$V_{S}=\beta(0.701 P-K s) A+0.299 P A \quad$ in $\left[L^{3}\right]$ 
In this second case, we have runoff only in the compartment $A_{R}$. Simulated runoff volume depends on $K s$ and $\beta$. Calibration with $K s$ allows us to fit runoff depth $\left(V_{S} / A\right)$ between 0 and $\alpha P$, i.e. rainfall reaching compartment $A_{R}$ $\left(A_{R}=\beta \mathrm{A}\right)$. Concerning $\beta$, note that the linear regression coefficient of the straight line of Eq. (27) is negative according to the conditions imposed by Eq. (24) (i.e. $K s>0.701 P$ ) meaning that an increase in $\beta$ tends to reduce the runoff volume. According to Eq. (27), calibration with $\beta$ allows us to fit runoff depth $\left(V_{S} / A\right)$ between 0 and $0.299 P$.

(iii) Third case: if $P_{R}$ and $P_{N R} \leq K s$, then $V_{S}=0$. The third case corresponds to a total infiltration of water on the plot.

In conclusion, the $\beta$ coefficient influences the simulated runoff volumes when rainfall intensities are not high enough to generate runoff in the compartment $A_{N R}$, but $\beta$ has no influence when rainfall intensities are high and generate runoff in both compartments. Consequently, a model that represents stemflow can generate runoff for maximum rainfall intensities $P x$ inferior to $K s$, leading to higher simulated runoff volumes when $P x / K s<1$.

\subsection{Model properties and calibration procedure}

\subsubsection{Model parameters}

The input variable of the model is the incident rainfall $P$, which was considered uniform on the whole plot area. The output of the model is a simulated hydrograph $Q_{S}(t)$, which was compared with the original measured hydrographs $Q_{O}(t)$ to assess model performances. The input rainfall $P$ is usually given as a function of time in the form of a histogram with a fixed time interval. Consequently, the other variables are also presented as functions of time, and the computations are carried out with the same fixed time interval. The model needs a total of nine parameters that may be measured, calculated, or calibrated. Four of these parameters could be measured and then fixed: the plot area $A$ and the representative parameters of the plant structure ( $A_{S f}, P_{S} f$, and LAI). In theory, another parameter can be measured in the field, namely $\beta$, but its measurement may be difficult because the boundaries of the runoff water pathways generated by stemflow vary in space and time, as shown by Cattan et al. (2009). Thus, $\beta$ should preferably be considered as a calibration parameter. Finally, there are five parameters that need to be calibrated: (i) two parameters for the stemflow function, coefficients $\alpha$ and $\beta$, (ii) one parameter for the production function, the average value of the saturated hydraulic conductivity $K s$, and (iii) two parameters for the transfer function, the lag time $\omega$ and the shape parameter $z$. However the number of parameters to be calibrated can be restricted to only four in the case of banana fields, because Cattan et al. (2007a) have shown that there is an empirical relation (see Eq. 13) between $\alpha$ and $\beta$. The sensitivity anal- ysis conducted on a representative flood event, as well as the different modelling strategies that will be presented later, will assess the variability of these four calibrated parameters.

\subsubsection{Parameterization strategies}

The usefulness of the stemflow function was tested by comparing strategies without and with stemflow. For that, we defined three approaches: one approach without a stemflow function - noted NoStem, and two approaches each with a stemflow function - noted Stem (1) and Stem (2). Fixed and calibrated parameters used in these approaches are presented in Table 1 and detailed hereafter:

(i) the NoStem approach is the "reference" approach because the rainfall reaching the ground is homogeneous (without a stemflow function). It is carried out in conditions of unknown $K s$, which was calibrated;

(ii) the Stem (1) approach is the first approach with a nonuniform rainfall reaching the ground (with a stemflow function). This approach is also in conditions of unknown $K s$, leading to calibrating $K s$ and fixing $\beta$;

(iii) the Stem (2) approach is the second approach with stemflow carried out in a condition of known $K s$, leading to fixing $K s$ and calibrating $\beta$.

In these three approaches, parameters of the transfer function $\omega$ and $z$ were calibrated.

Comparing the three approaches aimed to assess the effect of soil permeability ( $K s$ parameter) as well as the effect of stemflow ( $\beta$ parameter) on runoff production. Moreover, analysis of the shape of the simulated hydrographs according to the rainfall intensities helps identify the role of stemflow on runoff production, notably for low rainfall intensities.

\subsubsection{Performance criteria}

To analyse calibration results and to assess model performances, we used four criteria relative to the simulation of runoff depth, peakflow, and shape of the whole hydrograph.

Criteria for accuracy of runoff depth $S$ and peakflow $Q x$ were the relative errors $\varepsilon_{S i}$ and $\varepsilon_{Q x i}$ for event $i$ and $\varepsilon_{S}$ and $\varepsilon_{Q x}$ for $N$ events, respectively. The formula of relative errors $\varepsilon_{S i}$ and $\varepsilon_{S}$ are given below:

for one event : $\quad \varepsilon_{s i}=\frac{S s_{i}-S o_{i}}{S o_{i}}$

for $N$ events : $\quad \varepsilon_{s}=\frac{1}{N} \sum_{i=1}^{N}\left|\frac{S s_{i}-S o_{i}}{S o_{i}}\right|$

where $i$ is an index representing a flood event $(1 \leq i \leq N)$; $N$ is the total number of flood events used for calibration and validation; $S o_{i}$ is the measured runoff depth for event $i ; S s_{i}$ 
Table 1. Fixed and calibrated parameters for the three modelling approaches.

\begin{tabular}{ccccc}
\hline & \multicolumn{3}{c}{ Model functions and corresponding parameters } \\
Modelling approaches & Stemflow function & Production function & Transfer function \\
& $\beta$ & $K s$ & $\omega$ & $z$ \\
& {$[-]$} & {$\left[\mathrm{mm} \mathrm{h}^{-1}\right]$} & {$[\mathrm{min}]$} & {$[\mathrm{min}]$} \\
\hline NoStem & Not used & Calibrated & Calibrated & Calibrated \\
Stem (1) & Fixed & Calibrated & Calibrated & Calibrated \\
Stem (2) & Calibrated & Fixed & Calibrated & Calibrated \\
\hline
\end{tabular}

is the simulated runoff depth for event $i$. Criterion $\varepsilon_{S i}$ ranges between -1 and $+\infty$ and criterion $\varepsilon_{S}$ between 0 and $+\infty$. The optimum value for these two criteria is 0 , and we considered like Chahinian et al. (2006) that a value lower than $|0.25|$ corresponded to good model performances. Peakflow criteria $\varepsilon_{Q x i}$ and $\varepsilon_{Q x}$ were calculated according to Eqs. (28) and (29) by substituting the observed peakflow $Q x_{O i}$ and the simulated peakflow $Q x_{S i}$ by $S_{O i}$ and $S_{S i}$, respectively.

The shape of the whole hydrograph was assessed according two criteria: the Nash and Sutcliffe (1970) coefficient expressed for one event, $N S_{i}$ (Eq. 30), and for $N$ events, $N S$ (Eq. 31), and the root mean square error RMSE expressed for $N$ events (Eq. 32).

$$
\begin{aligned}
& N S_{i}=1-\left[\frac{\sum_{j=1}^{n_{i}}\left(Q o_{i j}-Q s_{i j}\right)^{2}}{\sum_{j=1}^{n_{i}}\left(Q o_{i j}-\bar{Q}_{i}\right)^{2}}\right] \text { for one event } \\
& N S=1-\left[\frac{\sum_{i=1}^{N} \sum_{j=1}^{n_{i}}\left(Q o_{i j}-Q s_{i j}\right)^{2}}{\sum_{i=1}^{N} \sum_{j=1}^{n_{i}}\left(Q o_{i j}-\bar{Q}\right)^{2}}\right]
\end{aligned}
$$

$\mathrm{RMSE}=\left[\frac{\sum_{i=1}^{N} \sum_{j=1}^{n_{i}}\left(Q o_{i j}-Q s_{i j}\right)^{2}}{\sum_{i=1}^{N} n_{i}}\right]^{1 / 2}$ for $N$ events

where $j$ is an index representing the time step in a flood event $i\left(1 \leq j \leq n_{i}\right) ; n_{i}$, the number of time steps in the flood event $i ; Q_{O i j}$, the observed discharge at time $j$ in the flood event $i ; Q_{S i j}$, the simulated discharge at time $j$ on the flood event $i ; \bar{Q}_{i}$, the mean value of discharge of the flood event $i$, and $\bar{Q}$, the mean value of all measured discharge of all flood events. $N S$ criteria range between $-\infty$ and 1 , with 1 signifying a perfect fit between simulated and observed hydrographs, and with negative values signifying that the arithmetic mean of the observed hydrograph is a better estimate than the simulated hydrograph. We considered in this study that a 0.8 value corresponded to good model performances. RMSE criteria range between 0 and $+\infty$, with 0 signifying a perfect fit between simulated and observed hydrographs. It should be noted that RMSE gives similar optimal parameters as the $N S$ criteria, thus we only used RMSE to assess model performances (it was not used in the calibration procedure).

\section{Study site}

\subsection{Experimental site}

\subsubsection{Field situation}

Measurements were carried out at the Neufchâteau experimental station $\left(16^{\circ} 04^{\prime} 38^{\prime \prime} \mathrm{N}, 61^{\circ} 36^{\prime} 04^{\prime \prime} \mathrm{W}, 250 \mathrm{~m}\right)$, on the windward side of Basse Terre, Guadeloupe (FWI). The Lesser Antilles are under a maritime humid tropical climate, and the interannual average for rainfall between 1952 and 2004 at Neufchâteau station was 3600 mm (Météo-France, 2004). The field was at "Espérance Haut", which has a $3000 \mathrm{~m}^{2}$ surface area with a $12 \%$ mean slope. The field was planted with banana in a square design $(2.35 \mathrm{~m} \times 2.35 \mathrm{~m})$, in $10 \mathrm{~cm}$ diameter holes on 21 February 2001. The previous crop was banana, followed by 8 -months fallow.

\subsubsection{Soil}

The soil is an Umbric Andosol (WRB, 2006) with a continuous macroscopic structure, with medium and fine tubular pores. Neither of the two horizons exhibited cracks at any time because the soil never dries out sufficiently due to the regularity of rainfall (Cattan et al., 2006). Soil in this site is strongly porous media with a total porosity reaching of 71 and $81 \%$ in $\mathrm{hA}$ and $\mathrm{hB}$, respectively (Cattan et al., 2007b), and may exhibit preferential flow patterns given the hydrophobic nature of their constituents, as generally observed for Andosols (Clothier et al., 2000; Poulenard et al., 2004). Concerning water pathways under the soil, Charlier et al. (2008) have shown that in this same pedoclimatic environment, lateral subsurface flow is limited in favour of 
percolation through the water table. This is particularly true because Andosols in the studied zone are developed on a very porous formation of ashes mixed with lapillis.

\subsubsection{Plant}

The banana plant has an impluvium shape. Its crown is made of verticilated leaves with a petiole and a midrib supporting two wide laminae. The Cavendish cultivar planted on the plot can reach $3 \mathrm{~m}$ in height; the average length and width of the leaves are $1.74 \mathrm{~m}$ and $0.72 \mathrm{~m}$, respectively. As stated in Sect. 2.1.2.3, on a banana plot planted in a square design $(2.35 \mathrm{~m} \times 2.35 \mathrm{~m})$, the measured values of LAI and the base of the plant $A_{S f}$ given by Cattan et al. (2007a) for a banana plant were: $\mathrm{LAI}=3.2$ for a full-grown banana plant, and $A_{S f}=0.047 \mathrm{~m}^{2}$. These characteristics do not change after flowering (around 6 months after plantation) when the banana canopy exhibited a maximal leaf area, the canopy from one banana plant overlapping with the adjacent plants. The model presented in this paper did not account for the lower stemflow effect before flowering because the selected rainfall events occurred after this period when the banana plantation was in full development.

\subsubsection{Rill network}

The plot was not tilled favouring a less marked network of rills on the ground surface. Hence, the network was more sinuous and less embedded than in a tilled plot, but was still observed. The network connects the concave zones of runoff propagation downstream of the pseudostem and also on drip zones between banana plants.

\subsection{Measurements}

The plot was hydraulically isolated from upstream runoff by 50 -cm-wide galvanized sheets pushed vertically $20 \mathrm{~cm}$ into the ground. The runoff from the plot was channelled to the outlet via a concrete-lined channel at the lower end of the plot, and hence to a venturi channel (type E 1253 AZ, Hydrologic, Grenoble, France). The head of water in the venturi channel was measured using a bubble flowmeter (ALPHEE 3010, Hydrologic, Grenoble, France) adapted to the narrow width of the venturi, with $8 \mathrm{~s}$ time lapse. Rainfall intensities were measured on the plot by one tipping-bucket rain gauge (ARG100, Campbell Scientific, Shepshed, Leicestershire, UK), with a sensitivity of $0.2 \mathrm{~mm}$ of rain per tip. The study period lasted from 6 December 2001 to 2 April 2002.

On these soils always close to saturation under a humid tropical climate, we assumed that the mean hydraulic conductivity measured in 2001 on the field using a controlledsuction disc infiltrometer at potential 0 by Cattan et al. (2006) was a reference value of the mean saturated hydraulic con- ductivity $K s$ of the plot. Mean $K s$ was $75 \mathrm{~mm} \mathrm{~h}^{-1}$ (standard deviation of $7.6 \mathrm{~mm} \mathrm{~h}^{-1}$ ) for five measurements at the ground surface. This relative homogeneity is probably due to the $K s$ measurements which took place only few months after plantation; suction disc infiltrometer measuring $K s$ on a small surface $(8 \mathrm{~cm}$ diameter cylinder). Moreover, $K s$ measurements performed using the double ring infiltration method (Bouwer, 1986) by Cattan et al. (2006) on the same type of soil show a mean $K s$ value of $67 \mathrm{~mm} \mathrm{~h}^{-1}$ (confidence interval $\left.[50,85] \mathrm{mm} \mathrm{h}^{-1}\right)$. Generally, on Andosol, we can have usually a larger range of values of around 35 to $350 \mathrm{~mm} \mathrm{~h}^{-1}$ according to agricultural management (Dorel et al., 2000).

\subsection{Characteristics of flood events}

To reduce the influence of soil surface characteristics (mulch, accumulation of material transported by runoff, etc.) on the hydrological response of the plot while characterizing the impact of rainfall partitioning, we selected rainfall events higher than $10 \mathrm{~mm}$ depth. A rainfall event was defined as a rainy period in which there was less than 15 min between two successive tips of the tipping bucket; the corresponding runoff period was defined as a period in which water flow was never interrupted for over $5 \mathrm{~min}$. Eighteen selected flood events were selected for model calibration and validation (Table 2). The 18 events were split at random between a set of 9 events for calibration and a set of 9 events for validation. Duration of events ranged between 28 and $242 \mathrm{~min}$, rainfall depth $P$ ranged between 10.0 and $139.2 \mathrm{~mm}$, mean rainfall intensity $\bar{P}$ between 11.0 and $47.2 \mathrm{~mm} \mathrm{~h}^{-1}$, maximum rainfall intensity over $5 \mathrm{~min} P x_{5}$ between 45.6 and $144.0 \mathrm{~mm} \mathrm{~h}^{-1}$, runoff depth $S$ between 1.5 and $44.0 \mathrm{~mm}$, peakflow $Q x$ between 6.8 and $35.71 \mathrm{~s}^{-1}$, and runoff coefficient $S / P$ between $9.3 \%$ and $36.0 \%$. Globally, as shown on Fig. 4 which presents $P x_{5}$, $S, Q x$, and $S / P$ as a function of $P$, the higher the rainfall depth, the higher the maximum rainfall intensity over $5 \mathrm{~min}$, the higher the runoff depth, and the higher the peakflow.

The selected rainfall events cumulated $530 \mathrm{~mm}$ of rainfall depth, i.e. $1 / 4$ of the total rainfall depth of the monitored period of 5 months (including the rainiest months of a hydrological year). Cattan et al. (2006) showed that rainfall events with a rainfall depth superior to $10 \mathrm{~mm}$ represented $4.5 \%$ of the 862 recorded events, and that rainfall events with a rainfall intensity superior to $72 \mathrm{~mm} \mathrm{~h}^{-1}$ (approximately equal to the mean $K s$ of the soil surface) represented $10.3 \%$. Consequently, in this context of rainfall regime of frequent light falls, we assume that events of calibration and validation sets fit with the main rainfall events occurring in a hydrological year. 
Table 2. Characteristics of flood events, sorted by increasing rainfall depth for each calibration and validation set.

\begin{tabular}{|c|c|c|c|c|c|c|c|c|c|}
\hline $\begin{array}{l}\text { Event } \\
\text { number }\end{array}$ & Date & $\begin{array}{l}\text { calibration } \\
\text { (C) and } \\
\text { validation } \\
\text { (V) set }\end{array}$ & $\begin{array}{c}\text { Duration } \\
\text { of flood } \\
\text { event } \\
D \\
\text { [min] }\end{array}$ & $\begin{array}{c}\text { Rainfall } \\
\text { depth } \\
P \\
\\
{[\mathrm{~mm}]}\end{array}$ & $\begin{array}{c}\text { Mean } \\
\text { rainfall } \\
\text { intensity } \\
\bar{P} \\
{\left[\mathrm{~mm} \mathrm{~h}^{-1}\right]}\end{array}$ & $\begin{array}{l}\text { Maximum } \\
\text { rainfall } \\
\text { intensity } \\
\text { over } 5 \mathrm{~min} \\
\quad \operatorname{Px}_{5} \\
{\left[\mathrm{~mm} \mathrm{~h}^{-1}\right]}\end{array}$ & $\begin{array}{c}\text { Runoff } \\
\text { depth } \\
\quad S \\
\\
{[\mathrm{~mm}]}\end{array}$ & $\begin{array}{l}\text { Peakflow } \\
\qquad x x \\
{\left[1 \mathrm{~s}^{-1}\right]}\end{array}$ & $S / P$ \\
\hline 1 & 27 Jan 2002 & & 38 & 10.6 & 31.8 & 64.8 & 1.8 & 6.8 & 17.2 \\
\hline 2 & 10 Dec 2001 & & 41 & 11.2 & 28.0 & 67.2 & 3.0 & 13.5 & 26.9 \\
\hline 3 & 20 Dec 2001 & & 57 & 13.0 & 16.2 & 52.8 & 2.8 & 8.2 & 21.2 \\
\hline 4 & 2 Apr 2002 & & 50 & 15.8 & 19.0 & 67.2 & 1.5 & 9.0 & 9.3 \\
\hline 5 & 16 Dec 2001 & $\mathrm{C}$ & 107 & 23.2 & 14.2 & 48.0 & 8.3 & 18.6 & 36.0 \\
\hline 6 & 9 Dec 2001 & & 60 & 24.4 & 28.7 & 91.2 & 6.0 & 18.7 & 24.7 \\
\hline 7 & 15 Dec 2001 & & 143 & 25.4 & 11.0 & 45.6 & 8.7 & 17.8 & 34.3 \\
\hline 8 & 21 Dec 2001 & & 71 & 47.6 & 40.1 & 110.4 & 13.9 & 25.6 & 29.2 \\
\hline 9 & 13 Dec 2001 & & 186 & 139.2 & 47.2 & 129.6 & 44.0 & 35.7 & 31.6 \\
\hline 10 & 10 Dec 2001 & & 28 & 10.0 & 23.1 & 48.0 & 1.9 & 10.8 & 19.4 \\
\hline 11 & 14 Dec 2001 & & 50 & 11.4 & 19.5 & 50.4 & 4.1 & 14.8 & 35.6 \\
\hline 12 & 11 Dec 2001 & & 32 & 12.6 & 36.0 & 64.8 & 3.5 & 15.3 & 27.7 \\
\hline 13 & 20 Dec 2001 & & 39 & 15.0 & 37.5 & 62.4 & 5.2 & 19.5 & 34.5 \\
\hline 14 & 11 Dec 2001 & $\mathrm{~V}$ & 49 & 23.2 & 28.4 & 69.6 & 6.4 & 16.4 & 27.5 \\
\hline 15 & 14 Dec 2001 & & 45 & 25.2 & 44.5 & 93.6 & 8.0 & 19.8 & 31.9 \\
\hline 16 & 10 Dec 2001 & & 64 & 27.8 & 28.8 & 76.8 & 7.6 & 18.3 & 27.3 \\
\hline 17 & 6 Dec 2001 & & 80 & 37.4 & 38.7 & 144.0 & 7.8 & 24.5 & 20.8 \\
\hline 18 & 2 Apr 2002 & & 242 & 57.0 & 15.3 & 62.4 & 8.2 & 12.7 & 14.4 \\
\hline
\end{tabular}

\subsection{Model parameterization for application on the study site}

\subsubsection{Hypothesis on redistribution processes within the plot}

Globally, the conceptual scheme of the model was based on observations of flowpaths carried out on the field, as well as by video monitoring during rainfall events (see Cattan et al., 2009). Due to the existence of a tortous rill network connecting the water pathways fed by stemflow to the outlet of the plot, we assume that all "produced" surface runoff reaches the bottom of the plot. In this setting, infiltration of runoff during the transit in the rill may occur. But it may occur only for the runoff volume for which runoff intensities are lower than $K s$, because, as assumed for the rest of the plot, the initial soil moisture state is always close to saturation. Thus, we have made the hypothesis that the runoff production follows the same process in the rill network and on the rest of the plot, leading to justify our choice of a lumped approach for modelling.

\subsubsection{Input data}

To relate rainfall to runoff at the plot scale, the hydrological time series of rainfall and runoff were synchronised on a 1 min time step. Thus, in the model application, the com-
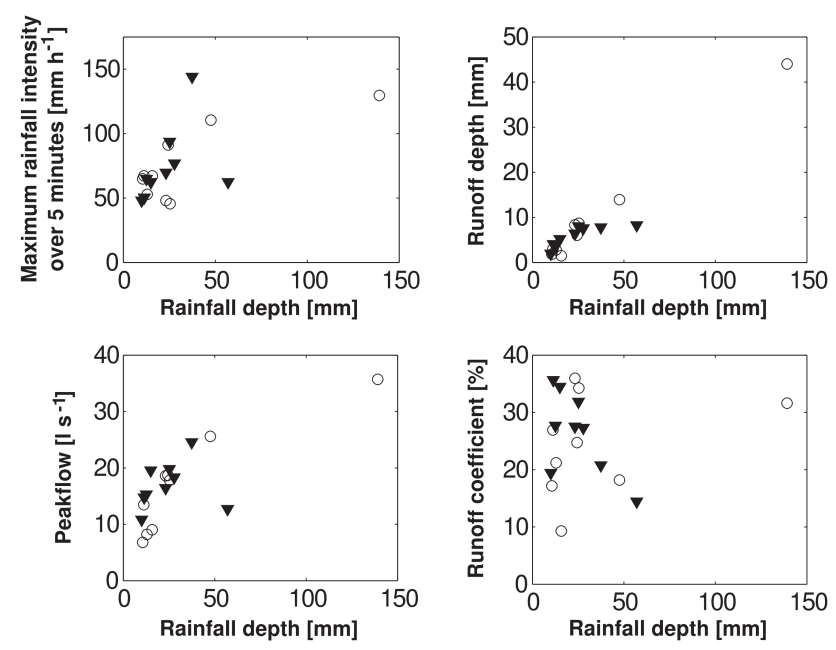

Fig. 4. Characteristics of flood events of the calibration set (o) and validation set $\mathbf{\nabla}$.

puting interval was $1 \mathrm{~min}$. Concerning input data relative to banana plot geometry, see Sect. 2.1.2.3. Concerning the three modelling approaches, the parameterization is detailed on Table 3. For NoStem, Ks was calibrated. For Stem (1), $\beta$ was set to $5 \%$ (this value was chosen from preliminary 
Table 3. Parameterization and performance criteria for calibration and validation sets for the three modelling approaches using collective calibration.

\begin{tabular}{|c|c|c|c|c|c|c|c|c|c|c|c|}
\hline \multirow[t]{2}{*}{ Approaches } & \multirow{2}{*}{$\begin{array}{c}\text { Event } \\
\text { numbers }\end{array}$} & \multirow{2}{*}{$\begin{array}{l}\text { calibration } \\
\text { (C) and } \\
\text { Validation } \\
\text { (V) sets }\end{array}$} & \multicolumn{4}{|c|}{$\begin{array}{l}\text { Fixed }^{\mathrm{a}} \text { and optimised } \\
\text { parameter values }\end{array}$} & \multicolumn{5}{|c|}{ Performance criteria } \\
\hline & & & $\begin{array}{c}\beta \\
{[-]}\end{array}$ & $\begin{array}{c}K s \\
{\left[\mathrm{~mm} \mathrm{~h}^{-1}\right]}\end{array}$ & $\begin{array}{c}\omega \\
{[\mathrm{min}]}\end{array}$ & $\begin{array}{c}z \\
{[-]}\end{array}$ & $\begin{array}{c}\varepsilon_{S} \\
{[-]}\end{array}$ & $\begin{array}{l}{ }^{\varepsilon} Q x \\
{[-]}\end{array}$ & $\begin{array}{l}\text { RMSE } \\
{\left[1 s^{-1}\right]}\end{array}$ & $\begin{array}{l}N S \\
{[-]}\end{array}$ & $\begin{array}{c}N S_{<5} \\
{[-]}\end{array}$ \\
\hline \multirow{2}{*}{ NoStem } & 1 to 9 & $\mathrm{C}$ & $\approx 1^{\mathrm{a}, \mathrm{b}}$ & 44.4 & 16.0 & 0.481 & 0.000 & 0.37 & 3.89 & 0.69 & -0.55 \\
\hline & 10 to 18 & $\mathrm{~V}$ & $\approx 1^{\mathrm{a}, \mathrm{b}}$ & 44.4 & 16.0 & 0.481 & 0.106 & 0.45 & 3.26 & 0.53 & -5.50 \\
\hline \multirow{2}{*}{ Stem (1) } & 1 to 9 & $\mathrm{C}$ & $0.05^{\mathrm{a}}$ & 60.5 & 10.9 & 0.485 & 0.000 & 0.18 & 2.42 & 0.88 & 0.35 \\
\hline & 10 to 18 & $\mathrm{~V}$ & $0.05^{\mathrm{a}}$ & 60.5 & 10.9 & 0.485 & 0.066 & 0.59 & 2.38 & 0.75 & -1.32 \\
\hline \multirow{2}{*}{ Stem (2) } & 1 to 9 & $\mathrm{C}$ & 0.00935 & $75.0^{\mathrm{a}}$ & 8.7 & 0.484 & 0.000 & 0.02 & 1.98 & 0.92 & 0.47 \\
\hline & 10 to 18 & V & 0.00935 & $75.0^{\mathrm{a}}$ & 8.7 & 0.484 & 0.166 & 0.53 & 2.08 & 0.81 & -0.36 \\
\hline
\end{tabular}

a fixed parameters

$\mathrm{b}$ parameterisation without accounting for stemflow

simulations) and $K s$ was calibrated. For Stem (2), $K s$ was set to $75 \mathrm{~mm} \mathrm{~h}^{-1}$ in accordance with the mean of $K s$ measurements in the field by Cattan et al. (2006), and $\beta$ was calibrated.

\subsubsection{Analysis of the indicators of the results}

To characterize low flows corresponding to recession periods, we defined a Nash and Sutcliffe coefficient $N S$ for measured discharges lower than $51 \mathrm{~s}^{-1}$, called $N S_{<5} i$ and $N S_{<5}$ for one and $N$ events, respectively (see Eqs. 30 and 31). In fact, $N S$ on the whole hydrograph favours simulation of the highest discharges at the expense of a good fit of low discharges. With $N S_{<5}$ and $N S_{<5} i$ criteria, we wish to better characterize the role of the stemflow function on the simulation of low flows. We applied $N S_{<5}$ and $N S_{<5}$ on a period when runoff was the least influenced by the initial conditions of the soil, i.e. on the recession period (generally occurring after the peak of rainfall) when the soil remained saturated.

To test the hypothesis that the incident rainfall concentration at the plant foot from stemflow generated runoff for rainfall intensities lower than $K s$, we compared maximal rainfall intensities $P x$ with calibrated $K s$ for the three modelling approaches. In the case study, the computing interval of $1 \mathrm{~min}$ was considered as unstable relative to measurement uncertainties. To smooth $P x$ for $1 \mathrm{~min}$, maximum rainfall intensities for $5 \mathrm{~min}, P x_{5}$, were used. Consequently, simulation results are presented as a function of the $P x_{5} / K s$ ratio, which is an adapted indicator of rainfall intensity during a flood event at the plot scale.

\subsubsection{Calibration procedure}

A collective calibration procedure was carried out manually on a set of nine events noted 1 to 9 . This calibration was identical for the three approaches, NoStem, Stem(1), and Stem (2). It involved two steps: (i) a calibration was performed to obtain a minimal value of the relative error $\varepsilon_{S}$ on the simulated runoff depth (calibration parameters $K s$ or $\beta$ according to the approaches - see Table 1), and then (ii) an optimisation of the shape of the hydrograph was done to obtain a maximal value of $N S$ criteria (calibration parameters $\omega$ and $z$ ). With this kind of calibration, the second step cannot influence $\varepsilon_{S}$ criteria, whereas the first step may slightly influence $N S$ criteria, which are partly linked to the simulated runoff depth.

Then, model performances were assessed according to the five criteria $\varepsilon_{S}, \varepsilon_{Q x}$, RMSE, $N S$, and $N S_{<5}$ for the calibration and validation sets. Within these sets, individual performances of the flood events - event by event - were assessed according to the four criteria $\varepsilon_{S i}, \varepsilon_{\mathrm{Qxi}}, N S_{i}$, and $N S_{<5} i$. Results are presented in Sect. 5.

\section{Model behaviour and parameter variability}

To improve the understanding of the model, we present in this section results of rainfall-runoff simulations on two events. First, simulations on an event with low and large rainfall intensities were chosen to illustrate the model behaviour according to the three modelling approaches NoStem, Stem (1), and Stem (2). Second, the sensitivity of runoff 
production to $K s$ and $\beta$ was determined on a mean rainfall event to illustrate the variability of the parameters described theoretically above.

\subsection{Illustration of the model behaviour}

To illustrate the model behaviour, Fig. 5 shows simulations on event 7 for the three approaches, NoStem, Stem (1), and Stem (2). This event was selected because it presented long periods with rainfall intensities lower than the mean $K s$ value. In Fig. 5 two long periods of residual rainfall appear before and after the rainfall peak, during which rainfall intensities were about $12 \mathrm{~mm} \mathrm{~h}^{-1}$ and systematically inferior to the $K s$ calibration value (i.e. a minimum of $13 \mathrm{~mm} \mathrm{~h}^{-1}$ for NoStem approach).

Figure 5 shows that during this period of residual rainfall (time $>100 \mathrm{~min}$ ), the NoStem modelling approach did not simulate runoff. Conversely, approaches Stem(1) and Stem (2) simulated a continuous discharge of about $2.51 \mathrm{~s}^{-1}$. In addition, we observed that for Stem (2), runoff volumes were under-estimated for peakflows. In fact, for high rainfall intensities there was no possible calibration of $\beta$ (first case of the previous theoretical analysis - see Sect. 2.4). In this case, runoff volume was thus strictly determined by the fixed $K s$ value of $75 \mathrm{~mm} \mathrm{~h}^{-1}$.

\subsection{Sensitivity analysis on a representative event}

To illustrate the model behaviour described theoretically above, we present a sensitivity analysis on a representative event. We have assumed that a sensitivity analysis carried out on a mean flood event was an indicator of the sensitivity of the model parameters on the other events. This analysis was carried out for event 16 on the four parameters $K s$, $\beta, \omega$, and $z$. This event was selected because its rainfall depth $P(27.8 \mathrm{~mm})$ and its maximal rainfall intensity over $5 \mathrm{~min} P x_{5}\left(76.8 \mathrm{~mm} \mathrm{~h}^{-1}\right)$ corresponded to the average $P$ and average $P x_{5}$ of the 18 events (Table 2). Calibration using the Stem (1) approach led to the following optimal parameter values: $K s=51.5 \mathrm{~mm} \mathrm{~h}^{-1}, \beta=0.05, \omega=7 \mathrm{~min}$, and $z=0.47$.

Regarding the sensitivity of runoff production to $K s$ and $\beta$, an interaction between these parameters generated an equifinality on runoff depth calibration because of their impacts on the rainfall-runoff partition at the soil surface. For this reason we wanted to identify the more sensitive calibration parameter, $K s$ or $\beta$ ? Figure 6 represents, on a semi-log scale, $\varepsilon_{S i}$ iso-values according to $K s$ and $\beta$. For a perfect fit of runoff depth (i.e. $\varepsilon_{S i}=0$ ), the higher the $K s$, the lower the $\beta$. $K s$ value for a $\beta$ close to 1 corresponds to the calibration value for approach NoStem, i.e. $39 \mathrm{~mm} \mathrm{~h}^{-1}$. Below this $K s$ threshold, variations of $\beta$ cannot offset the insufficient infiltration, and consequently the model overestimates the runoff depth. The shape of the curve for $\varepsilon_{S i}=0$ shows that for $K s$ values increasing from 39 to $200 \mathrm{~mm} \mathrm{~h}^{-1}$, which correspond to the range of $K s$ values measured on the field, $\beta$ decreases from 1 (equivalent to a model without stemflow, i.e. NoStem approach) to 0.0002 . This means that the model is more sensitive to $\beta$ than to $K s$. Finally, if we wish to have only one calibration parameter for runoff simulations, $\beta$ should be selected rather than $K s$.

Regarding the sensitivity of hydrographs to $\omega$ and $z$, parameter variability of the diffuse wave equation has been largely investigated (e.g. Moussa and Bocquillon, 1996; Yu et al., 2000; Chahinian et al., 2006; Tiemeyer et al., 2007). Our results agreed with literature values and confirmed that the higher the $\omega$ and the $z$, the lower the $Q x$ and the transfer velocity.

\section{Comparison of modelling approaches "without" and "with" stemflow}

\subsection{Global analysis of calibration and validation sets}

\subsubsection{Calibration results}

Simulations of the calibration set carried out to optimise the runoff volume $\left(\varepsilon_{S}=0\right)$ showed that the shape of the simulated hydrograph was better simulated with the stemflow function than without (Table 3): for the calibration set, $N S$ was 0.69 , 0.88 , and 0.92 , and RMSE was $3.89,2.42$, and $1.981 \mathrm{~s}^{-1}$, for NoStem, Stem(1), and Stem(2), respectively. To assess the model performances on all events, a split-sample test (Klemeš, 1986) was conducted. This test considers that each set of events (event numbers 1 to 9 and 10 to 18 in our case study - Table 2) should be used in turn for calibration and validation. Taking events 10 to 18 for calibration and 1 to 9 for validation led to similar NS and RMSE values for calibration, that is to say $0.61,0.80$, and 0.82 for $N S$, and 4.36, 3.13, and $2.961 \mathrm{~s}^{-1}$ for RMSE, for the same three approaches, respectively.

Regarding performance criteria of peakflows $\left(\varepsilon_{Q x}\right)$ in Table 3 for the calibration set, peakflows were overestimated for all approaches but were better simulated with the stemflow function $\left(\varepsilon_{Q x} 0.36,0.18\right.$, down to 0.02 for NoStem, Stem(1), and Stem(2), respectively). But with poorer results, low flows were unequally simulated $\left(N S_{<5}\right.$ $-0.55,0.35$, up to 0.47 for NoStem, Stem (1), and Stem (2), respectively). Finally, these results showed that the modelling approach with stemflow globally improved model performances.

Moreover, the model with stemflow adequately simulated runoff volumes, with a mean $K s$ value equal to the mean of field measurements $\left(75 \mathrm{~mm} \mathrm{~h}^{-1}\right)$ : for NoStem, calibrated $K s$ was $44.4 \mathrm{~mm} \mathrm{~h}^{-1}$, whereas for Stem (1), Ks was higher $\left(60.5 \mathrm{~mm} \mathrm{~h}^{-1}\right)$. Additionally, we noticed that the lag time $\omega$ decreased by nearly half when using the stemflow function, with values of 16,11 , and $9 \mathrm{~min}$ for approaches NoStem, Stem(1), and Stem(2), respectively. This decrease in 

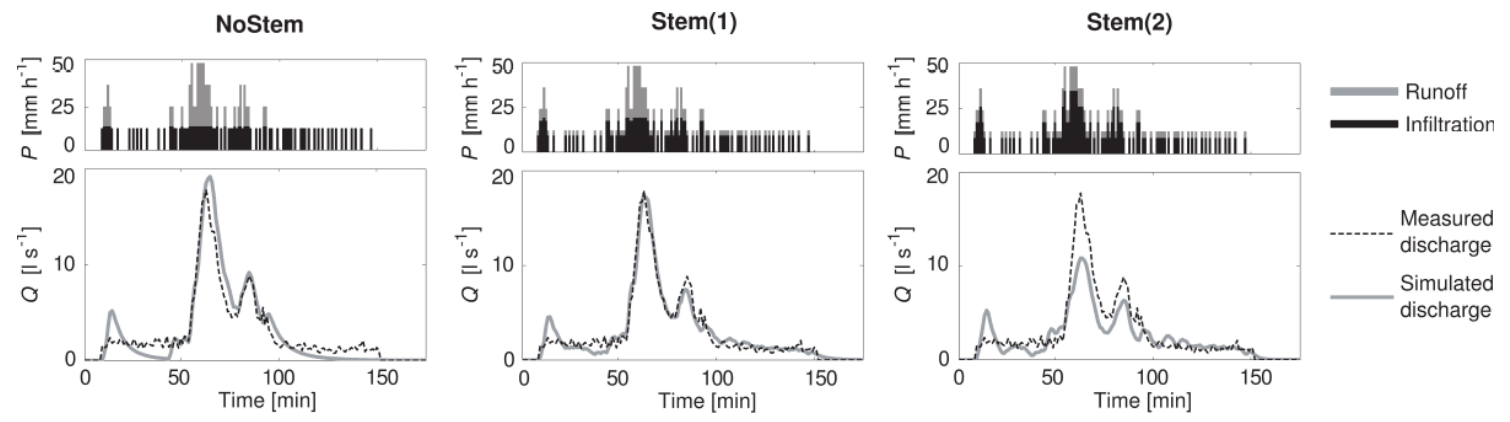

Fig. 5. Simulated hydrographs of event 7 for the three approaches: without stemflow NoStem and with stemflow Stem (1) and Stem (2) using individual calibration. $P$ is the rainfall and $Q$ the discharge at the plot outlet.

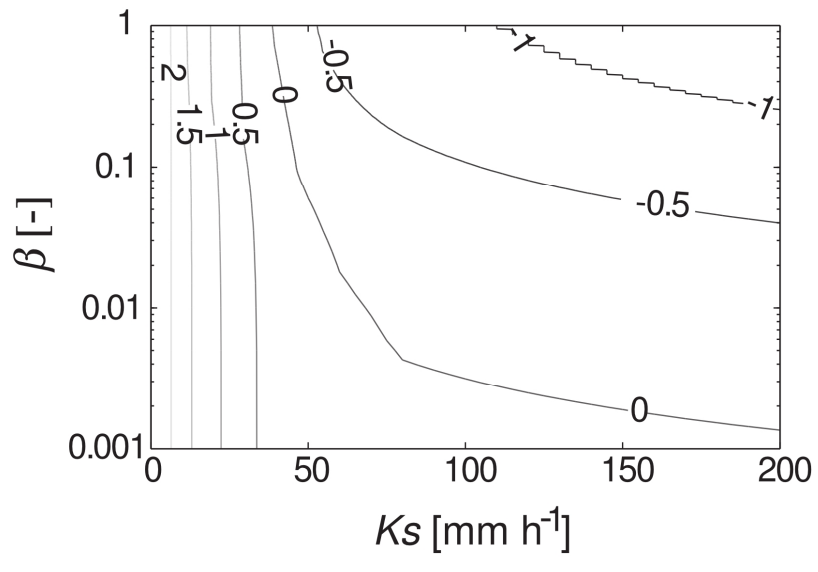

Fig. 6. Sensitivity analysis of the $K s$ and $\beta$ parameters on simulated runoff volume for event 16 ; lines represent iso-values of the relative error on volume $\varepsilon_{S i}$.

response time indicates that the transfer velocity on the plot increased when using the stemflow function. In fact, the lower transfer velocity with approach NoStem contributed to stretching the flood hydrograph and thus to simulating runoff for residual rainfall in the recession period, although the production function did not produce runoff during this period. Conversely, approaches Stem (1) and Stem (2) produced runoff for residual rainfall in the recession period. Consequently, good simulations were obtained with faster transfer. Finally, the shape parameter $z$ varied little from an approach to another, and was about 0.48 .

\subsubsection{Validation results}

Globally, the three approaches simulated runoff volumes well on the validation set with $\varepsilon_{S}$ values inferior to 0.17 . As seen for calibration results, modelling approaches with stemflow improved simulation of flood hydrographs for validation sets (Table 3): $N S$ was $0.53,0.75$, and 0.81 , and RMSE was 3.26, 2.38, and $2.081 \mathrm{~s}^{-1}$, for NoStem, Stem (1), and Stem (2), respectively. For the split-sample test detailed above, $N S$ was $0.61,0.89$, and 0.90 , and RMSE was 2.97, 1.58 , and $1.511 \mathrm{~s}^{-1}$ for the three approaches, respectively. However, contrary to the calibration results, the other performance criteria of peak and low flows were poorly simulated for the three approaches with $\varepsilon_{Q x}$ values superior to 0.45 , and with negative $N S_{<5}$ values (Table 3 ). To better understand the disparity of the simulation results of the calibration and validation sets, the next section will analyse the model performances event by event.

\subsection{Event by event analysis}

Performance criteria of the model simulations event by event - shown in Figs. 7 and 8 - are plotted in Fig. 9 as a function of $P x_{5} / K s$, which represents the ratio between the maximal rainfall intensity over $5 \mathrm{~min}$ and the saturated hydraulic conductivity.

Regarding the criteria on runoff volume, NoStem shows an increasing function of $\varepsilon_{S i}$ vs. $P x_{5} / K s$, leading to an under-estimation of the lowest rainfall events and an overestimation of the highest. This $\varepsilon_{S i}$ vs. $P x_{5} / K s$ relationship became less marked for Stem (1) and disappeared for Stem (2), meaning that the stemflow function improved the simulation of runoff volume for all events, notably with low rainfall intensities. The same trend was observed for criteria $\varepsilon_{Q x i}$, indicating that the simulation of the peakflow is also better with stemflow.

Concerning the simulation of the hydrograph, modelling with a stemflow function improved the shape of the whole hydrograph as well as the shape of low flows, especially for low rainfall intensities. In fact, the number of events out of 12 with $P x_{5} / K s<1$ having $N S_{i}$ and $N S_{<5} i$ values superior to 0.8 were 0 and 0 for NoStem, 7 and 6 for Stem (1), and 7 and 4 for Stem (2), respectively.

Finally, NoStem, Stem (1), and Stem (2) gave good performances for events having a $P x_{5} / K s$ close to 1 (in other words for which the maximum rainfall intensity was close to the calibrated $K s$ value; events $6,14,15$, and 16 in Figs. 7 and 8). And the Stem (1) and Stem (2) approaches 

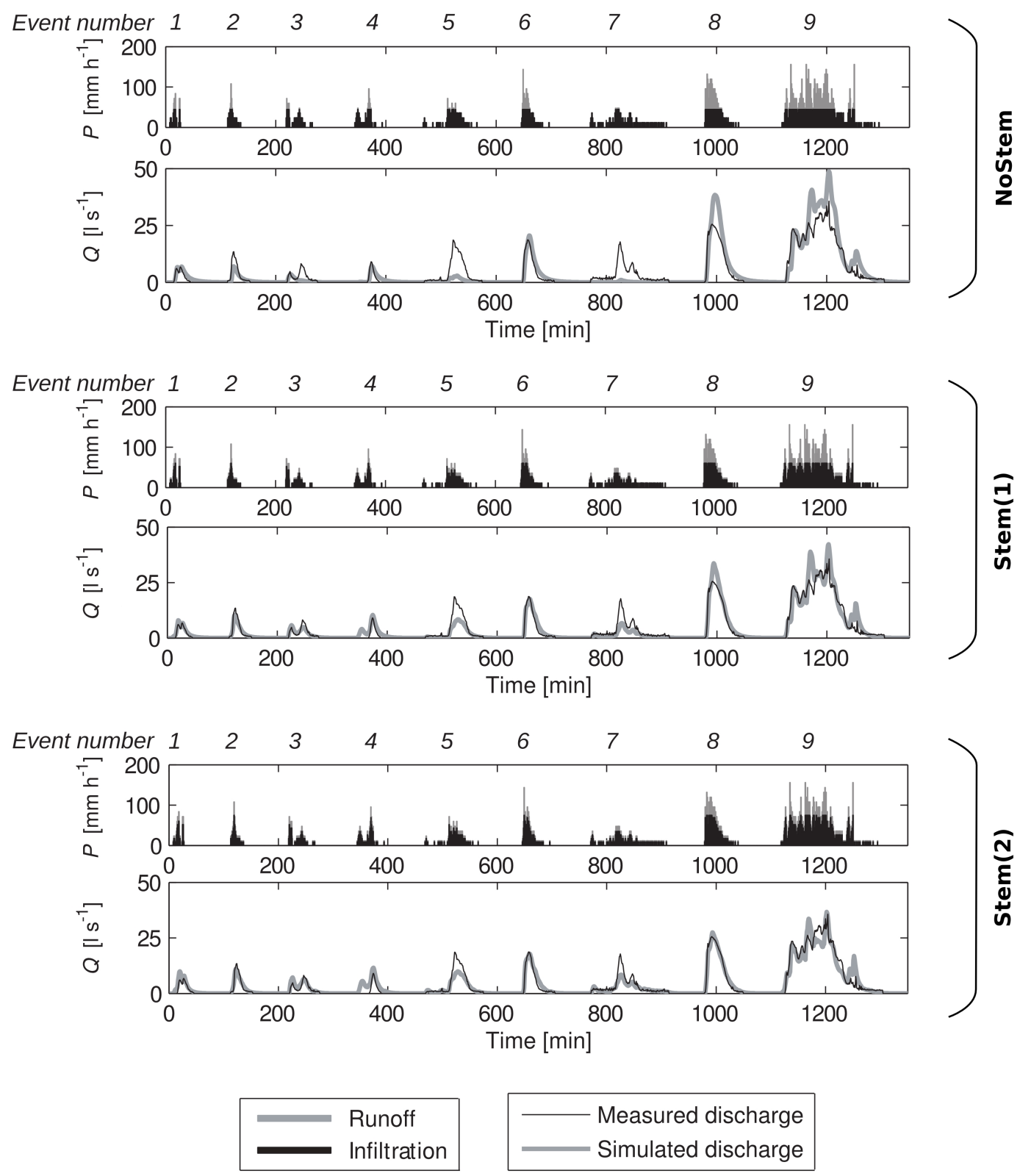

Fig. 7. Simulation results for calibration events set for the three approaches: without stemflow NoStem and with stemflow Stem(1) and Stem (2). $P$ is the rainfall and $Q$ the discharge at the plot outlet. Notice that the various events are presented on the same time axis.

considerably improved runoff modelling for rainfall events with low intensities, notably those lower than the measured $K s$. On the other hand, these results showed that $\beta$ can be an efficient calibration parameter when $K s$ is measured in situ.

\section{Discussion and conclusion}

The aim of this paper was to to develop a simple hydrological interception/stemflow model, based on physical and geometrical concepts (accounting for the structure and prop- erties of the plant) rather than on empirical concepts, and having few parameters easily available on the field. Our results, in the case of a banana field, show that taking into account the rainfall partitioning by vegetation in a runoff model improved discharge simulation at the plot scale. This approach was consistent with the high permeability values measured on the field and accounts for the production of runoff for rainfall intensities lower than surface saturated hydraulic conductivity Ks. This modelling approach was lumped at the plot scale, in which we developed a stemflow function that was coupled with a production function and a transfer 

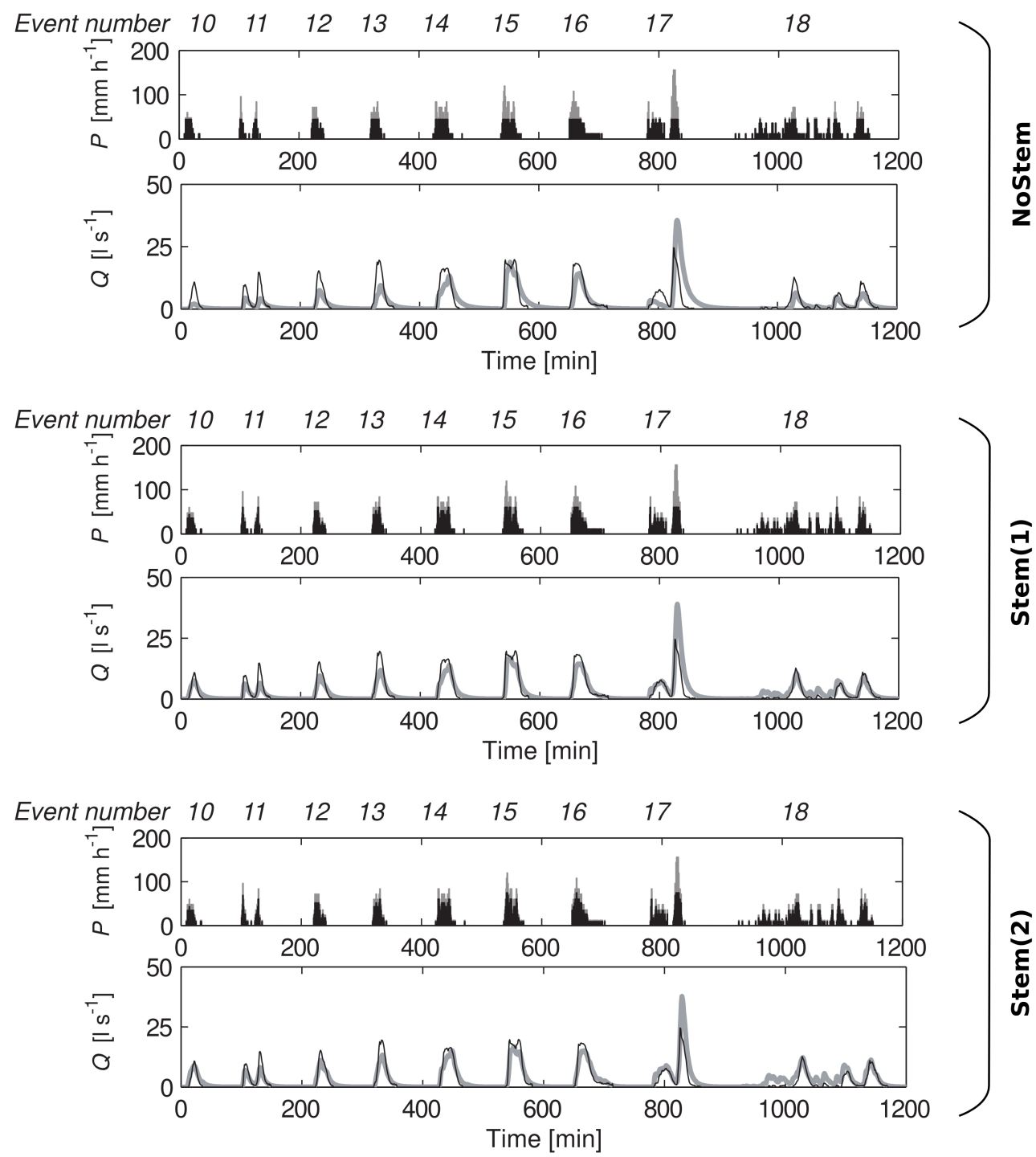

Runoff

Measured discharge

Infiltration

Simulated discharge

Fig. 8. Simulation results for validation events set for the three approaches: without stemflow NoStem and with stemflow Stem(1) and Stem (2). $P$ is the rainfall and $Q$ the discharge at the plot outlet. Notice that the various events are presented on the same time axis.

function. The application on a banana field under tropical rainfalls in Guadeloupe gave good results $\left(N S_{i}>0.6\right.$ for 14 events out of 18) for a wide range of rainfall events from 10 to $140 \mathrm{~mm}$ depth. This last point highlights the robustness of the model and allows it to be considered for application on long time series.

Our study showed the influence of plant canopy on hydrological processes at the $3000 \mathrm{~m}^{2}$ plot scale. Simulations showed that the rainfall concentration at the plant foot by stemflow could increase the runoff coefficient at this scale. This was done in the context of plants with a high funnelling ratio cropped on permeable Andosol under high rainfall in- tensities. Concerning low flows, although results without and with stemflow showed that it was difficult to simulate runoff during low rainfalls, low flows were better modelled with stemflow. This result is coherent with the decrease in $K s$ observed at the end of the rainfall event by Cattan et al. (2009) at the banana plant scale. In fact, this decrease in permeability generates more runoff and is equivalent to a concentration of rainwater at the soil surface in our modelling approach with stemflow.

Under tropical climate, rainfall redistribution by plant canopy is not the only relevant process involved in runoff when rainfall intensities are less than the $K s$ measured on the 

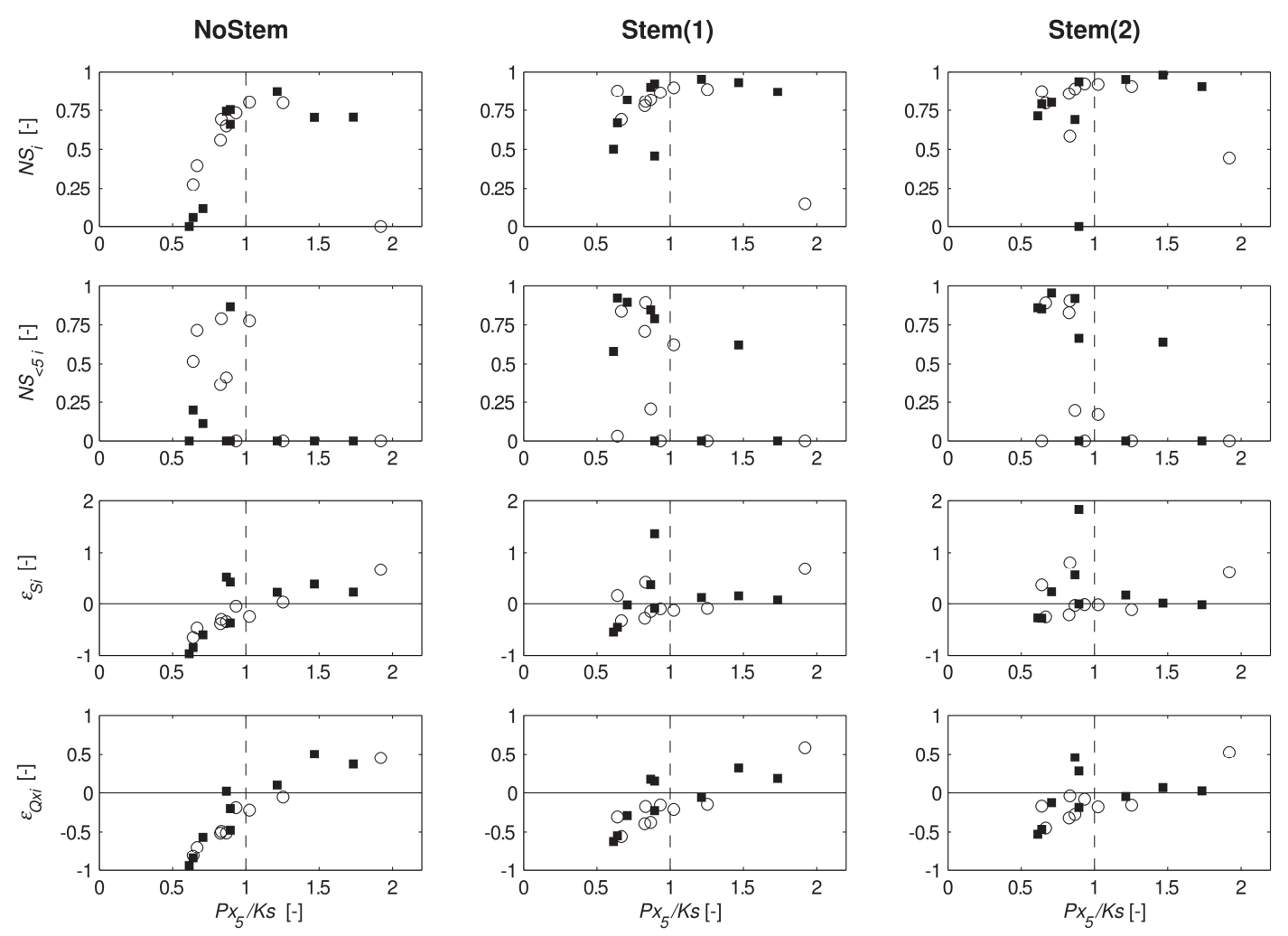

Fig. 9. Results of performance criteria for the calibration a and validation (o) sets for the three approaches: without stemflow NoStem and with stemflow Stem (1) and Stem (2). $P x_{5} / K s$ is the ratio between the maximal rainfall intensity for 5 min and the saturated hydraulic conductivity, $N S_{i}$ and $N S_{<5 i}$ are the Nash and Sutcliffe coefficients on the whole hydrograph and on discharge lower than $51 \mathrm{~s}^{-1}$ on flood recession, respectively, $\varepsilon_{S i}$ and $\varepsilon_{\mathrm{Qxi}}$ the relative errors on volume and on peakflow, respectively; for graphical readability, null values are used as a substitute for negative values of $N S_{i}$ and $N S_{<5} i$ criteria.

plot. Two other processes may occur. The first one is soil crusting which reduces $K s$ value between infiltration measurement and runoff assessment. The second is related to air trapped in the pores in the top soil since the runoff events in the channels are short and rapid. In our case on Andosol, given the high cohesion of soil aggregate, crusting was not observed on the plot. Concerning air inclusion, we think it was unlikely because additional observations during double ring infiltration measurement performed on the same type of soil by Cattan et al. (2006) showed that permanent regime was obtained after a few minutes. In consequence, the fact that in our study case mainly during rainfall events of intermediate strength the runoff is higher than would be expected, points in the direction of stemflow.

One limitation of the modelling approach lies in the concept of the hydraulic compartmentation of the plot, with one compartment receiving a water pathway from stemflow. In fact, the physical measurement of the stemflow coefficient $\beta$, which determines the area of both compartments, may be difficult because the boundaries of the water pathways vary in space and time as shown by Cattan et al. (2009). Thus, this conceptual two-compartment scheme implies that the parameter of the stemflow function should remain calibrated.
The major implication of this study concerns the management of water fluxes in a cultivated plot. First, our study shows that, to account for rainfall partitioning between runoff and infiltration, changes in the structure and arrangement of cropping species should be considered as well as the more traditional soil management techniques (plant cover, mulching, soil tillage...). Second, the structure and arrangement of cropping species should be taken into account to globally manage transfers in and out of the plot. Indeed, the great heterogeneity of water fluxes at the soil surface that are induced by plant cover may influence transport of solute elements (fertilizers and pesticides) or solid elements (erosion). Some authors have shown the role of banana stemflow in drainage water on transport of nitrate and potassium (Sansoulet et al., 2007) and of pesticides (Saison et al., 2008), confirming the need to consider these processes. This is especially true since applications of agrochemicals on banana fields are not spatially distributed over the whole area: in the case of banana, applications are localized around the plant collar, i.e. in zones of high water fluxes from stemflow.

In prospect, the improved simulation of low flows with our modelling approach provided opportunities to model low intermittent rainfalls corresponding to rainfall events of long 
duration with relatively low intensities, situations for which authors like Yu et al. (2000) and Chahinian et al. (2006) have noted the modelling difficulties. Finally, considering the influence of vegetation on runoff generation at the plant and the plot scales, its influence on hydrological processes at a larger scale, that of the hillslope and the catchment scales, have to be assessed. The proposed stemflow function integrated into a lumped model at the plot scale can be used in distributed hydrological models at the catchment scale to characterize vegetation impact on hydrological processes.

Acknowledgements. This study was funded by the Guadeloupe Region (FWI), the French Ministry of Ecology and Sustainable Development, and the European Community under the project "Assessment of water-pollution risks associated with agriculture in the French West Indies: management at the catchment scale".

Edited by: M. Mikos

\section{References}

Abbott, M. B., Bathurst, J. C., Cunge, J. A., O'Connell, P. E. and Rasmussen, J.: An introduction to the European Hydrological System - Systeme Hydrologique Europeen, "SHE”, 2: Structure of a physically-based, distributed modelling system, J. Hydrol., 87(1-2), 61-77, 1986.

Ajayi, A. E., Van de Giesen, N., and Vlek, P.: A numerical model for simulating Hortonian overland flow on tropical hillslopes with vegetation elements, Hydrol. Process., 22(8), 1107-1118, 2008.

Belk, E. L., Markewitz, D., Rasmussen, T. C., Carvalho, E. J. M., Nepstad, D. C. and Davidson, E. A.: Modeling the effects of throughfall reduction on soil water content in a Brazilian Oxisol under a moist tropical forest, Water Resour. Res., 43, W08432, doi:10.1029/2006WR005493, 2007.

Bouten, W., Schaap, M. G., Bakker, D. J. and Verstraten, J. M.: Modelling soil water dynamics in a forested ecosystem. I: A site specific evaluation, Hydrol. Process., 6(4), 435-444, 1992.

Bouwer, H.: Intake rate: cylinder infiltrometer, in: Methods of Soil Analysis, Part 1. Physical and Mineralogical Properties, Monograph 9, Methods of Soil Analysis, Part 1. Physical and Mineralogical Properties, Monograph 9, ASA, Madison, WI, 825-843, 1986.

Cattan, P., Cabidoche, Y.-M., Lacas, J.-G. and Voltz, M.: Effects of tillage and mulching on runoff under banana (Musa spp.) on a tropical Andosol, Soil Till. Res., 86(1), 38-51, 2006.

Cattan, P., Bussière, F., and Nouvellon, A.: Evidence of large rainfall partitioning patterns by banana and impact on surface runoff generation, Hydrol. Process., 21(16), 2196-2205, 2007 a.

Cattan, P., Voltz, M., Cabidoche, Y.-M., Lacas, J.-G., and Sansoulet, J.: Spatial and temporal variations in percolation fluxes in a tropical Andosol influenced by banana cropping patterns, J. Hydrol., 335(1-2), 157-169, 2007b.

Cattan, P., Ruy, S., Cabidoche, Y.-M., Findeling, A., Desbois, P., and Charlier, J.-B.: Effect on runoff of rainfall redistribution by the impluvium-shaped canopy of banana cultivated on an An- dosol with a high infiltration rate, J. Hydrol., 368(1-4), 251-261, 2009.

Chahinian, N., Moussa, R., Andrieux, P., and Voltz, M.: Accounting for temporal variation in soil hydrological properties when simulating surface runoff on tilled plots, J. Hydrol., 326(1-4), 135-152, 2006.

Charlier, J.-B.: Fonctionnement et modélisation hydrologique d'un petit bassin versant cultivé en milieu volcanique tropical, Ph.D. thesis, Université des Sciences et Techniques du Languedoc, Montpellier II, 246 pp., 2007.

Charlier, J.-B., Cattan, P., Moussa, R., and Voltz, M.: Hydrological behaviour and modelling of a volcanic tropical cultivated catchment, Hydrol. Process., 22(22), 4355-4370, 2008.

Clothier, B.E., Vogeler, I. and Magesan, G.N.: The breakdown of water repellency and solute transport through a hydrophobic soil, J. Hydrol., 231-232, 255-264, 2000.

Crockford, R. H. and Richardson, D. P.: Partitioning of rainfall into throughfall, stemflow and interception: effect of forest type, ground cover and climate, Hydrol. Process., 14(16-17), 29032920, 2000.

Cunge, J., Holly, F. M. and Verwey, A.: Practical Aspects of Computational River Hydraulics, Pitman Advanced Publishing Program, London, UK, 420 pp., 1980.

Dorel, M., Roger-Estrade, J., Manichon, H., and Delvaux, B.: Porosity and soil water properties of caribbean volcanic ash soils, Soil Use Manage., 16, 133-140, 2000.

Gash, J. H. C., Lloyd, C. R., and Lachaud, G.: Estimating sparse forest rainfall interception with an analytical model, J. Hydrol., 170(1-4), 79-86, 1995.

Green, W. A. and Ampt, G. A.: Studies on soil physics, 1: The flow of air and water through soils, J. Agr. Sci., 4(1), 1-24, 1911.

Harris, D.: The partitioning of rainfall by a banana canopy in St. Lucia, Windward Islands, Trop. Agr., 74, 198-202, 1997.

Hayami, S.: On the propagation of flood waves, Disaster Prevention Research Institute Bull., Kyoto University, 1, 1-16, 1951.

Herwitz, S. R.: Infiltration-excess caused by Stemflow in a cycloneprone tropical rainforest, Earth Surf. Proc. Land, 11(4), 401-412, 1986.

Horton, R. E.: The role of infiltration in the hydrologic cycle, Transactions, American Geophysical Union, 14, 446-460, 1933.

Keim, R. F. and Skaugset, A. E.: A linear system model of dynamic throughfall rates beneath forest canopies, Water Resour. Res., 40(05), W05208, doi:10.1029/2003WR002875, 2004.

Klemeš, V.: Operational testing of hydrological simulation models, Hydrolog. Sci. J., 31(1), 13-24, 1986.

Levia, D. F. J. and Frost, E. E.: A review and evaluation of stemflow literature in the hydrologic and biogeochemical cycles of forested and agricultural ecosystems, J. Hydrol., 274, 1-29, 2003.

Liang, W.-L., Kosugi, K. i., and Mizuyama, T.: A three-dimensional model of the effect of stemflow on soil water dynamics around a tree on a hillslope, J. Hydrol., 366(1-4), 62-75, 2009.

Llorens, P. and Domingo, F.: Rainfall partitioning by vegetation under Mediterranean conditions. A review of studies in Europe, J. Hydrol., 335, 37-54, 2007.

Marks, K. and Bates, P. D.: Integration of high-resolution topographic data with floodplain flow models, Hydrol. Process., 14, 2109-2122, 2000.

Meteo-France: Bulletin metéorologique de la Guadeloupe: 
récapitulatif annuel, Meteo-France, Abymes, Guadeloupe, France, 2004.

Morel-Seytoux, H. J.: Derivation of equations for variable rainfall infiltration, Water Resour. Res., 14(4), 561-568, 1978.

Moussa, R. and Bocquillon, C.: Algorithms for solving the diffusive wave flood routing equation, Hydrol. Process., 10(1), 105-123, 1996.

Moussa, R., Voltz, M., and Andrieux, P.: Effects of the spatial organization of agricultural management on the hydrological behaviour of a farmed catchment during flood events, Hydrol. Process., 16(2), 393-412, 2002.

Moussa, R. and Bocquillon, C.: On the use of the diffusive wave for modelling extreme flood events with overbank flow in the floodplain, J. Hydrol., 374(1-2), 116-135, 2009.

Nash, J. E. and Sutcliffe, J. V.: River flow forecasting through conceptual models part I : a discussion of principles, J. Hydrol., 10(3), 282-290, 1970.

Philip, J. R.: The theory of infiltration: 4. Sorptivity and algebraic infiltration equations, Soil Sci., 84, 257-267, 1957.

Poulenard, J., Michel, J. C., Bartoli, F., Portal, J. M., and Podwojewski, P.: Water repellency of volcanic ash soils from Ecuadorian p\&aacute;ramo: effect of water content and characteristics of hydrophobic organic matter, Eur. J. Soil Sci., 55(3), 487-496, 2004.

Richards, L. A.: Capillary conduction of liquids through porous medium, Physics, 1(5), 318-333, 1931.

Rutter, A. J., Kershaw, K. A., Robins, P. C. and Morton, A. J.: A predictive model of rainfall interception in forests. I. Derivation of the model from observations in a plantation of Corsican pine, Agr. Meteorol., 9, 367-384, 1971.
Saison, C., Cattan, P., Louchart, X. and Voltz, M.: Effect of spatial heterogeneities of water fluxes and application pattern on cadusafos fate on banana-cultivated andosols, J. Agr. Food Chem., 56(24), 11947-11955, 2008.

Sansoulet, J., Cabidoche, Y. M., and Cattan, P.: Adsorption and transport of nitrate and potassium in an Andosol under banana (Guadeloupe, French West Indies), Eur. J. Soil. Sci., 58(2), 478489, 2007.

Sansoulet, J., Cabidoche, Y.-M., Cattan, P., Ruy, S. and Simunek, J.: Spatially Distributed Water Fluxes in an Andisol under Banana Plants: Experiments and Three-Dimensional Modeling, Vadose Zone J. , 7(2), 819-829, 2008.

Singh, V. P.: Accuracy of kinematic wave and diffusion wave approximations for space independent flows, Hydrol. Process., 8(1), 45-62, 1994.

Tiemeyer, B., Moussa, R., Lennartz, B. and Voltz, M.: MHYDASDRAIN: A spatially distributed model for small, artificially drained lowland catchments, Ecol. Model., 209(1), 2-20, 2007.

Van Dijk, A. I. J. M. and Bruijnzeel, L. A.: Modelling rainfall interception by vegetation of variable density using an adapted analytical model. Part 1. Model description, J. Hydrol., 247(3-4), 230-238, 2001.

WRB (Ed.), World reference base for soil resources, World Soil Resources, No. 103, FAO, Rome, 2006.

Yu, B., Sombatpanit, S., Rose, C. W., Ciesiolka, C. A. A. and Coughlan, K. J.: Characteristics and modeling of runoff hydrographs for different tillage treatments, Soil Sci. Soc. Am. J., 64(5), 1763-1770, 2000. 